\title{
Recurrence of disease activity during pregnancy after cessation of fingolimod in multiple sclerosis
}

\author{
Ingrid Meinl, Joachim Havla, Reinhard Hohlfeld and Tania Kümpfel
}

\section{Abstract}

Background: Fingolimod is an effective treatment for active relapsing-remitting multiple sclerosis (MS). Discontinuation of therapy may be followed by recurrence of disease activity. Thus, female MS patients may be at risk of relapse during pregnancy after stopping fingolimod.

Objectives and methods: To report the disease course during pregnancy of five women who interrupted therapy with fingolimod for pregnancy.

Results: All patients experienced relapses during pregnancy and/or postpartum after stopping fingolimod. Conclusion: The risk of recurrence of disease activity during pregnancy after stopping fingolimod may be substantial. This should be considered and discussed with MS patients who are planning to become pregnant.

Keywords: Fingolimod, pregnancy, recurrence of disease activity, multiple sclerosis

Date received: 29 June 2017; revised: 9 August 2017; accepted: 21 August 2017

With the availability of effective disease-modifying drugs (DMTs), it is not uncommon that female patients who have active relapsing-remitting multiple sclerosis (RRMS) reconsider pregnancy after stabilization of their disease. Therapy with fingolimod is recommended to be discontinued at least two months before planned conception in female patients. ${ }^{1}$ Here, we report on the disease course during pregnancy and up to 12 months after delivery of five women with RRMS who stopped therapy with fingolimod because they were planning to become pregnant (four cases) or accidentally became pregnant (one case).

\section{Case series}

All patients were consecutively seen in our outpatient clinic at the Institute of Clinical Neuroimmunology. Clinical characteristics and magnetic resonance imaging (MRI) scans were collected, and all patients examined during the visit at our institute. Patient numbers, clinical data, and the disease course before, during, and up to 12 months after pregnancy are shown in Table 1 and Figure 1(a). All patients had active RRMS before therapy with fingolimod with relapses during therapy with interferon-beta or glatiramer acetate. Four patients decided to discontinue fingolimod for pregnancy planning after stabilization of their MS during therapy with fingolimod. Subsequently, all four became pregnant after a mean of 11 weeks (range 4-20weeks). One patient (patient 3) with very active MS before fingolimod therapy, accidentally became pregnant and stopped therapy at week 12 of gestation. During the 5 months of fingolimod therapy, she clearly stabilized. All five patients experienced relapses during pregnancy after stopping fingolimod (mean: 17weeks, range: 12-20weeks). Discontinuation of fingolimod prior to pregnancy was followed by severe relapses just before pregnancy and/ or during the first trimester in four patients and by additional postpartum relapses in two of them. Patient 3 who continued fingolimod into early pregnancy due to inadvertent pregnancy experienced a relapse during the third trimester and one relapse postpartum. MRI data were available in four patients, and all showed disease progression (Figure 1(b)). Three women resumed therapy with fingolimod after delivery. Two of them remained stable thereafter; one woman (patient 3) changed therapy to natalizumab due to recurrent lymphocytopenia and also remained stable so far. In all patients, lymphocyte counts were reduced during fingolimod treatment and returned to normal levels after stopping fingolimod.
Multiple Sclerosis Journal 2018, Vol. 24(7) 991-994 DOI: 10.1177 1352458517731913

(C) The Author(s), 2017. Reprints and permissions: http://www.sagepub.co.uk/ journalsPermissions.nav
Correspondence to: T Kümpfel Institute of Clinical Neuroimmunology, Biomedical Center and

University Hospital, LudwigMaximilians-Universität München, Marchioninistr. 15, 81377 Munich, Germany.

tania.kuempfel@med.unimuenchen.de

Ingrid Meinl Joachim Havla Tania Kümpfel Institute of Clinical Neuroimmunology, Biomedical Center and University Hospital, LudwigMaximilians-Universität München, Munich, Germany Reinhard Hohlfeld Institute of Clinical Neuroimmunology, Biomedical Center and University Hospital, LudwigMaximilians-Universität München, Munich, Germany/ The Munich Cluster for Systems Neurology (SyNergy), Munich, Germany 
Table 1. Clinical characteristics of patients.

\begin{tabular}{|c|c|c|c|c|c|c|c|}
\hline Patient & $\begin{array}{l}\text { Age } \\
\text { (years) }\end{array}$ & $\begin{array}{l}\text { Disease } \\
\text { duration } \\
\text { (years) }\end{array}$ & $\begin{array}{l}\text { Therapy } \\
\text { before } \\
\text { fingolimod }\end{array}$ & $\begin{array}{l}\text { Disease activity } \\
\text { in the year before } \\
\text { fingolimod }\end{array}$ & $\begin{array}{l}\text { Duration of } \\
\text { fingolimod } \\
\text { therapy } \\
\text { (months) }\end{array}$ & $\begin{array}{l}\text { Time to relapse } \\
\text { after stopping } \\
\text { fingolimod } \\
\text { (weeks) }\end{array}$ & $\begin{array}{l}\text { Number of } \\
\text { relapses after } \\
\text { stopping } \\
\text { fingolimod }\end{array}$ \\
\hline 1 & 27 & 5 & IFN, GLAT & $\begin{array}{l}\text { Two relapses, } \\
\text { multiple new } \\
\text { lesions on MRI }\end{array}$ & 36 & 12 & 1 \\
\hline 2 & 32 & 10 & GLAT & $\begin{array}{l}\text { Four relapses, } \\
\text { multiple new } \\
\text { lesions on MRI }\end{array}$ & 17 & 20 & 3 \\
\hline 3 & 32 & 6 & IFN, GLAT & $\begin{array}{l}\text { Four relapses, two } \\
\text { new lesions on MRI }\end{array}$ & 5 & 16 & 2 \\
\hline 4 & 31 & 9 & IFN, GLAT & $\begin{array}{l}\text { Two relapses, } \\
\text { multiple new } \\
\text { lesions on MRI }\end{array}$ & 30 & 20 & 2 \\
\hline 5 & 30 & 9 & IFN, GLAT & $\begin{array}{l}\text { One relapse, new } \\
\text { lesion on MRI }\end{array}$ & 16 & 16 & 2 \\
\hline
\end{tabular}

\section{Discussion}

In this case series, all women who promptly got pregnant after stopping fingolimod experienced a return of disease activity during pregnancy. Re-occurrence or even rebound of disease activity 4-16 weeks after discontinuation of fingolimod was previously reported in settings unrelated to pregnancy. 2,3 More recently, four patients with severe rebound after withdrawal of fingolimod have been described; two of them stopped fingolimod for pregnancy planning. ${ }^{4}$ Both of them experienced a relapse 8-12 weeks after stopping fingolimod. ${ }^{4}$ In addition, there are single reports of dramatic rebounds of disease activity during pregnancy following withdrawal of fingolimod. ${ }^{5,6}$ In our patients, relapses occurred with a mean of 17 weeks after stopping fingolimod and were accompanied by Expanded Disability Status Scale (EDSS) progression in three of the five patients. Because of early conception after fingolimod discontinuation, the period of increased risk fell into pregnancy. Pregnancy is known to be protective in MS, especially during the second and third trimenon. ${ }^{7}$ Our observations indicate that this protective effect is not sufficient to prevent recurrence of disease activity during pregnancy after stopping fingolimod. According to current recommendations, fingolimod should be discontinued at least 8 weeks before conception. As fingolimod is placed in the US Food and Drug Administration (FDA) pregnancy category C, 1,8 continuation of fingolimod during pregnancy is definitely not an option for patients who wish to become pregnant while under treatment with fingolimod. Nevertheless inadvertent pregnancies during fingolimod therapy - as in our case series - have been reported world-wide.
Similar observations were made in patients treated with natalizumab, raising the question whether natalizumab should be continued at least until conception or even during the entire pregnancy. ${ }^{9,10}$ Limited experience in patients who continued natalizumab during pregnancy indicates this may be mitigate the disease course, and apart from mild hematologic alterations, no major adverse events have been observed so far. ${ }^{10}$ However, because reproductive risks cannot be excluded, continuation of natalizumab during pregnancy is only recommended for women in whom the potential benefit justifies the potential risk.

A limitation of this observation is the small number of female patients who got pregnant after stopping fingolimod. We cannot exclude a bias since female patients with a favorable disease course during pregnancy after stopping fingolimod may not present to our outpatient clinic. Therefore, a detailed analysis of risk factors for disease activity during pregnancy after cessation of fingolimod is not possible.

Since continuation or restarting fingolimod during pregnancy is not an option, specific counseling of patients before pregnancy is important. In female patients with highly active MS who are in their reproductive age, future pregnancies should be discussed before starting fingolimod therapy, and contraception is strongly recommended. If future pregnancy is considered a realistic option, therapeutic alternatives which can be administered until conception or throughout pregnancy, or have a prolonged effect lasting throughout pregnancy, should be considered. 


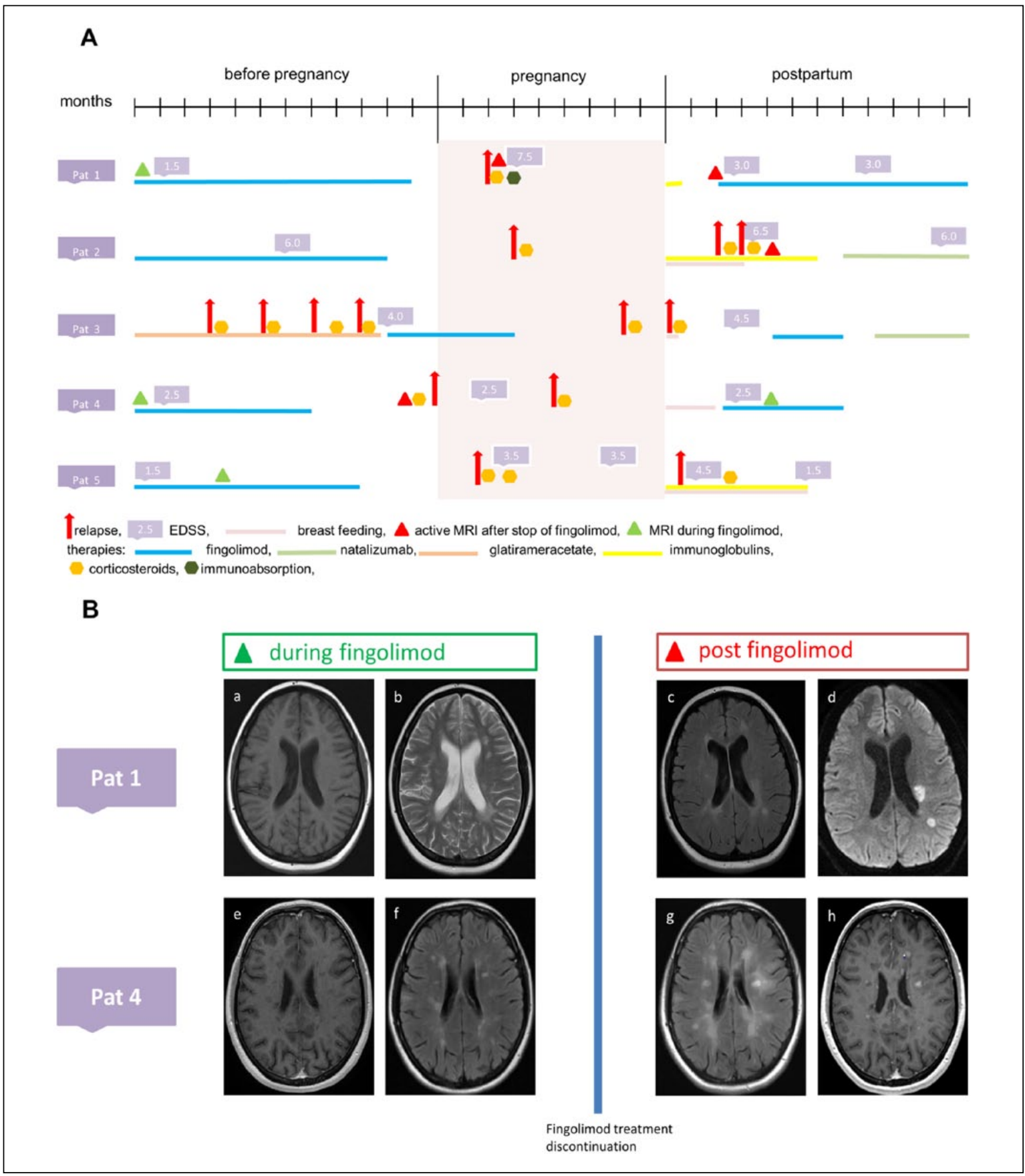

Figure 1. (A) Disease course before, during, and after pregnancy in five patients who stopped fingolimod and (B) MRI scans of patient 1 and 4 before pregnancy and after discontinuation of fingolimod: ( $a$ and $b$ ) cerebral MRI of patient 1 before pregnancy during fingolimod treatment and (c and d) 12 weeks after stopping fingolimod showing two new/ enlarging hyperintense lesions on axial fluid-attenuated inversion recovery (FLAIR) images with diffusion restriction in the diffusion-weighted image; ( $\mathrm{e}$ and $\mathrm{f}$ ) cerebral MRI of patient 4 before pregnancy during fingolimod therapy and ( $\mathrm{g}$ and h) 16 weeks after stopping fingolimod showing several new lesions on FLAIR, with contrast enhancement.

Declaration of Conflicting Interests

The author(s) declared the following potential conflicts of interest with respect to the research, authorship, and/or publication of this article: I.M. declares no potential conflicts of interest with respect to this article. J.H. received speaker honoraria, travel expenses, and personal compensations from Merck, Biogen, Roche, Bayer Healthcare, Sanofi, and Novartis Pharma. R.H. received grant support from Bayer, Biogen, Genzyme-Sanofi, Merck Serono, 
Visit SAGE journals online journals.sagepub.com/ home/msj

(SAGE journals
Novartis, and Teva and personal fees from Actelion, Bayer, Biogen, Genzyme-Sanofi, Medday, Merck Serono, Novartis, Roche, and Teva. T.K. received travel expenses and speaker honoraria from Bayer Healthcare, Teva Pharma, Merck, Novartis Pharma, Sanofi Aventis/Genzyme, CLB Behring, Roche Pharma, and Biogen as well as grant support from Bayer Schering AG, Novartis, and Chugai Pharma.

\section{Funding}

The author(s) received no financial support for the research, authorship, and/or publication of this article.

\section{References}

1. Karlsson G, Francis G, Koren G, et al. Pregnancy outcomes in the clinical development program of fingolimod in multiple sclerosis. Neurology 2014; 82: 674-680.

2. Havla JB, Pellkofer HL, Meinl I, et al. Rebound of disease activity after withdrawal of fingolimod (FTY720) treatment. Arch Neurol 2012; 69: 262-264.

3. Hatcher SE, Waubant E, Nourbakhsh B, et al. Rebound syndrome in patients with multiple sclerosis after cessation of fingolimod treatment. JAMA Neurol 2016; 73: 790-794.
4. Gündüz T, Kürtüncü M and Eraksoy M. Severe rebound after withdrawal of fingolimod treatment in patients with multiple sclerosis. Mult Scler Relat Disord 2017; 11: 1-3.

5. Sempere AP, Berenguer-Ruiz L and Feliu-Rey E. Rebound of disease activity during pregnancy after withdrawal of fingolimod. Eur J Neurol 2013; 20: e109-110.

6. Novi G, Ghezzi A, Pizzorno M, et al. Dramatic rebounds of MS during pregnancy following fingolimod withdrawal. Neurol Neuroimmunol Neuroinflamm 2017; 4: e377.

7. Convavreux C, Hutchinson M, Hours MM, et al. Rate of pregnancy-related relapse in multiple sclerosis. $N$ Engl J Med 1998; 339: 285-291.

8. Bove R, Alwan S, Friedman JM, et al. Management of multiple sclerosis during pregnancy and the reproductive years: A systematic review. Obstet Gynecol 2014; 124: 1157-1168.

9. Martinelli V, Colombo B, Dalla Costa G, et al. Recurrent disease-activity rebound in a patient with multiple sclerosis after natalizumab discontinuations for pregnancy planning. Mult Scler 2016; 22: 1506-1508.

10. Haghikia A, Langer-Gould A, Rellensmann G, et al. Natalizumab use during the third trimester of pregnancy. JAMA Neurol 2014; 171: 891-5895. 